\title{
The Co-Movement between Non-GM and GM Soybean Prices in China: Evidence from Dalian Futures Market (2004-2014)
}

\author{
Nanying Wang ${ }^{1} \&$ Jack E. Houston ${ }^{1}$ \\ ${ }^{1}$ Department of Agricultural and Applied Economics, The University of Georgia, USA \\ Correspondence: Nanying Wang, Department of Agricultural and Applied Economics, The University of Georgia, USA
}

Received: March 30, 2016

Accepted: June 8, 2016

Available online: June 23, 2016

doi:10.11114/aef.v3i4.1643

URL: http://dx.doi.org/10.11114/aef.v3i4.1643

\begin{abstract}
The price variability of agricultural commodities reached record levels in 2008, and again more recently in 2010 . This raises concerns that this increased price volatility would be temporal or structural. There are two soybean futures contracts in China: non-GM and GM. With the emergence of the GM soybean contract in 2004, the components of non-GM futures price volatility might have changed.

This study examines the volatility determinants as well as seasonality of non-GM and GM soybean futures prices traded in Dalian Commodity Exchange from 2005 to 2014. Also, we test the co-movement between these two soybeans markets. We analyze the volatility by incorporating changes in important economic variables into the Dynamic Conditional Correlation-Generalized Autoregressive Conditional Heteroskedastic (DCC-GARCH) model. This research provides statistical evidence that the futures prices of soybeans in China are being influenced by the increasing consumption of soybeans, the import quantity of soybean, the trading volume in futures market and weather. We also find spillover effect from non-GM to GM in soybean markets. A better understanding of the volatility determinants provides important additional information for various market participants, including commodity traders, hedgers, arbitrageurs, exchanges and regulatory agencies.
\end{abstract}

Keywords: China, DCC-GARCH Model, time-varying correlation, macroeconomic

\section{Introduction}

China is the world's largest producer and importer of non-GMO soybeans. In China's domestic market, soybean is a very significant agricultural commodity used as a major staple for human consumption, for conversion into human-consumable oil, and as an important animal feed ingredient. The price variability of agricultural commodities reached record levels in 2008, and again more recently in 2010 (Schneph, 2008). This raises concerns that this increased price volatility would be temporal or structural. The Chinese soybean futures market is the second largest in the world, after the CME group, in terms of trading volumes. There are two soybean futures contracts in China: non-GM and GM. Due to the dominant market share of trading volume, the non-GM contract is the representative of China's soybean markets. However, the introduction of the new GM contracts in 2004 presents a number of new opportunities for hedging/managing/speculating price risk, but also presents new challenges due to the difficulty of measuring expected volatility.

Volatility is a directionless measure of the extent of the variability of a price. It is a numerical measure of the risk faced by individual investors and financial institutions. Increasing risk would lead to inefficient resource allocation for producers, merchandisers, and speculators. It also has the potential to limit access to food in developing countries that have lower incomes and depend on imports. To measure expected volatility, it is very important to understand the relationship between these two soybean, their price determinants, and the underlying factors behind their price fluctuation. GM soybean is a close substitute of non-GM soybean, and therefore fluctuations in the price of GM soybean should result in corresponding fluctuations in non-GM soybean, vice versa. However, there is no literature before price volatilities of non-GM soybean and GM soybean are correlated or not. Consequently, it is important to analyze these two markets simultaneously to determine the factors behind their price volatility.

This research examines the influence of nine relevant factors on monthly soybeans futures prices. Price determinants include demand and supply factors. Macroeconomic factors affecting commodity prices have been studied in the literature. We use the industrial production index of China as a proxy of China's economic growth. Economic growth 
results in increased demand for goods, and therefore may generates an increase in demand for soybean. Weather plays an important role in the demand side of soybean markets. To capture the impact of weather, dummies for planting, growing, storage periods are used. On the supply side, storage levels are among the determinants of soybean prices. We use the ratio of stock and usage of soybean in China to account for this effect. Also, the production quantity of non-GM soybean in China is considered.

The estimation period covers a volatile period - the Global Financial Crisis -it enables to assess the effect of changing economic conditions on the volatility of soybean. We made a specification with a dummy variable for this event. We also consider the speculative and hedging influences in China's futures market, represented by trading volume. Other variables found to affect soybean prices including crude oil price; the weighted exchange rate between China and three other major import partners, which are U.S., Brazil and Argentina; and finally, the total import quantity of China from U.S., Brazil and Argentina is considered due to its large amount each year.

The purpose of this study is two-fold. First, we investigate the dynamic correlation across non-GM and GM soybean futures, with a focus on the persistency correlation across these two soybean futures prices traded on the Dalian Commodity Exchange. Further, Factors like percentage changes of industrial production index, trading volume, etc. are used to test whether they affect soybean price volatility. Our results can assist market participants better understanding which direction volatility in soybean go when levels of these factors change.

DCC-GARCH model is used to estimate volatility spillover effects and dynamic conditional correlation. Our study answers the following research questions: Does volatility in non-GM soybean prices have a spillover effect on the volatilities of GM soybean or vice versa? Which economic and natural factors most explain volatility in soybean markets? This study differentiates from previous studies in that it is the first to analyze the persistency of relation between non-GM and GM soybean futures prices in China.

This study can provide some knowledge of the conditions in Chinese agricultural commodity futures markets. It also contributes to securities pricing, portfolio optimization, developing hedging and regulatory strategies, etc. It is also in the interests of international market participants from countries like Canada, the USA, Australia and the European Union, who are the major grain exporters to China. In addition, the findings of this paper have relevant policy implications in asset allocation and risk management in designing agricultural commodity portfolios for investment decisions.

The study finds that the two soybean futures have high persistency. In addition, the study finds that the time-varying conditional correlation between non-GM and GM soybean futures is influenced by trading volume, ratio of stock and use, Chinese production and import level and the financial crisis. It also shows high volatility in the growing season.

\section{Literature Review}

Many researchers offer contributions to finance agricultural research by explaining the volatility process. Kenyon at al. (1987) show that corn, wheat, and soybeans futures price volatility is affected by seasons, lagged volatility, and loan rates. Sørensen (2002) concludes that the seasonal components for corn, soybeans, and wheat futures peak about two to three months before the beginning of harvest. It has been established that volatility is time-varying (Koekebakker and Lien 2004), highly persistent (Jin and Frechette 2000), and affected by supply and demand inflexibilities (Hennessy and Wahl 1996). Karali and Thurman (2010) investigate the determinants of daily price volatility in U.S. corn, soybeans, wheat, and oats futures markets. They identify Samuelson effect and the strong seasonality in all above four commodities. Chen et al. (2010) found that exchange rates are very useful in forecasting future commodity prices but not vice versa.

More recent studies consider a time period when China had already developed its futures market and became the largest soybean importer. Liu (2002) suggests that the large-volume trading is an important source of futures volatility in the Chinese soybean futures market. Chan et al (2004) studied China's soybean, wheat and found that negative returns appear to have a greater impact on volatility than positive returns do, while volume has a positive effect on volatility. China started a new trading system in 2002 to separate the trading of imported GMO soybean from domestically produced non-GMO soybean. Zheng et al (2012) examined the short run and long run price integration in the new trading system. However, little effort has been dedicated to the study of the joint movements among the prices of non-GM and GM soybean.

\section{Model}

Engle (2002) proposed a DCC-GARCH model where the conditional correlations amongst variables were allowed to be dynamic by including a time dependent component in the conditional correlation matrix. The main merit of DCC-GARCH model is that it accounts for changes in both the mean and variance of the time series. In addition, DCC-GARCH model estimates correlation coefficients of the standardized residuals and so accounts for heteroscedasticity directly (Chiang et al., 2007). Also, DCC-GARCH has the ability to adopt a student-t distribution of 
variances, which is more appropriate in capturing the fat-tailed nature of the distribution of index returns (Pesaran and Pesaran, 2009).

The DCC-GARCH approach has been widely used in recent papers investigating notably the linkages between bond prices (Antonakakis, 2013), stock prices (Cai, Chou and Li, 2009 or Bali and Engle, 2010), stock and bond prices (Yang, Zhou and Wang, 2009) with an extension to commodity futures (Silvennoinen and Thorp, 2013). We adopt the bivariate DCC-GARCH model in our study and modify it to include exogenous variables that might have an impact on the conditional volatility.

We measure the monthly return from holding a futures contract on month $\mathrm{t}$ as

$$
r t=100 \times\left(\ln F_{t}-\ln F_{t-1}\right)
$$

where $F_{t}$ is monthly settlement price of the futures contract on the last day of month $\mathrm{t}$.

Assume that soybean market returns from the two series are bivariate normally distributed with zero mean and conditional variance-covariance matrix Ht, our bivariate DCC-GARCH model can be presented as follows:

$$
\left\{\begin{array}{l}
r_{t}=\mu_{t}+\varepsilon_{t} \mid I_{t-1} \rightarrow N\left(\mathrm{O}, H_{t}\right) \\
H_{t} \equiv D_{t} R_{t} D_{t}+G^{\prime} G X_{t}
\end{array}\right.
$$

The returns on the soybeans is fat tailed or leptokurtic where a normal distribution assumption is not appropriate. Our remedy for this is to use a Student-t distribution setting. That is, the conditional distribution $u_{t} \mid \Omega_{t-1} \rightarrow f_{\text {Student }}\left(u_{t} ; v\right)$, where $v$ is the degree of freedom parameter.

In these formulas, $r_{t}$ is the $(2 \times 1)$ vector of the returns on soybean prices; $\varepsilon_{t}$ is a $(2 \times 1)$ vector of zero mean return innovations conditional on the information available at time $\mathrm{t}-1 ; \mu_{i, t}=\delta_{i 0}+\delta_{i 1} r_{i, t-1}$ for market $i$; $\mathrm{G}$ is the $(2 \times 2)$ lower triangular coefficient matrix on the exogenous variable $X_{t} ; D_{t}$ is a $(2 \times 2)$ diagonal matrix with elements on its main diagonal being the conditional standard deviations of the returns on each market in the sample and $R_{t}$ is the $(2 \times 2)$ conditional correlation matrix. $D_{t}$ and $R_{t}$ are defined as follows:

$$
D_{t}=\operatorname{diag}\left(h_{1 t}^{1 / 2} \cdots h_{22 t}^{1 / 2}\right)
$$

where $h_{i i t}$ is chosen to be a univariate $\operatorname{GARCH}(1,1)$ process;

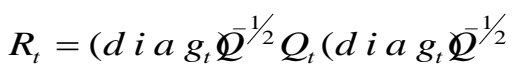

where $Q_{t}=(1-\alpha-\beta) \bar{Q}+\alpha u_{t-1} u_{t-1}^{\prime}+\beta Q_{t-1}$ refers to a $(2 \times 2)$ symmetric positive definite matrix with $u_{i t}=\varepsilon_{i t} / \sqrt{h_{i t}}, \bar{Q}$ is the $(2 \times 2)$ unconditional variance matrix of $u_{t}$, and $\alpha$ and $\beta$ are non-negative scalar parameters satisfying $\alpha+\beta \prec 1$.

The DCC model is constructed to permit a two-stage estimation of $H_{t}$. During the first step, a univariate GARCH model is fitted for each of the assets and the estimates of $h_{i i t}$ are obtained. In the second step, the asset returns are transformed by their estimated deviations and used to calculate the parameters of the conditional correlation. The log-likelihood function for the DCC model can be written as follows:

$$
L=-\frac{1}{2} \sum_{t}\left(k \log (2 \pi)+\log \left|H_{t}\right|+r_{t}^{\prime} H_{t}^{-1} r_{t}\right)
$$

The conditional correlation coefficient $\rho_{i j}$ between two markets $i$ and $j$ is expressed by the following equation:

$$
\rho=\frac{(1-\alpha-\beta) \overline{q_{i j}}+\alpha u_{i, t-1} u_{j, t-1}+\beta q_{i j, t-1}}{\left((1-\alpha-\beta) \overline{q_{i i}}+\alpha u_{i, t-1}^{2}+\beta q_{i i, t-1}\right)^{1 / 2}\left((1-\alpha-\beta) \overline{q_{j j}}+\alpha u_{j, t-1}^{2}+\beta q_{j j, t-1}\right)^{1 / 2}}
$$

where $q_{i j}$ refers to the element located in the $i$ th row and $j$ th column of the symmetric positive definite matrix $Q_{t}$. 


\section{Data}

We study non-GM and GM futures contracts that are traded on the Dalian Commodity Exchange (DCE). Both futures contracts have expiry dates in January, March, May, July, September and November. They are traded until the 10th trading day of the delivery month. Standard contract size is 10 metric tons and price is quoted as CNY per metric ton. We construct price daily time series for both soybeans by rolling over the third nearby contracts. When the futures price moves into the maturity month, we use the futures price for the next maturity month. We then use the price of the last day of the month as the proxy for the monthly soybean price. Futures price data are obtained from Datastream 5.1 provided by Thomson Reuters. Our sample covers the period from January 2005 to January 2014.

Commodity price volatility has been attributed to a number of factors, including demand and supply factors. Also, factors such as the integration of energy markets, macroeconomic conditions, and financial speculation all have been identified as key drivers of commodity price volatility (Masters and White 2008; Mitchell 2008; Irwin et al. 2008, 2009, 2010; Tangermann 2011). The following factors are considered as potentially overriding the factors leading to volatility of soybean prices in China's market. All these variables are recorded monthly and not seasonal adjusted.

For the macroeconomic factors, industrial production index is used to represent the Chinese macro-economic environment. Further, changes in exchange rates may reallocate purchasing power and price incentives across countries without changing the overall food supply-demand balance. Here we use the weighted average of the foreign exchange value of the CNY, which is based on the value of CNY compared to the currencies of major China trading partners of soybeans, which are U.S. (Dollar), Brazil (Brazil) and Argentian (Peso). Here we include percentage changes in "Industrial production index" and "weighted average of the foreign exchange value of the CNY" in the DCC GARCH model. The data utilized is obtained from DATASTRAM, FRED and the Central Bank of Argentina.

Inventory can reduce volatility so long as stocks are accumulated in periods of excess supply and released in times of excess demand. Because the important role inventories play in stabilizing demand and supply shocks, we include inventory data in our volatility analysis. We use the percentage change of stocks-to-use ratio computed with the series of "Ending Stocks" and "Total Use" of soybean of China published in World Agricultural Supply and Demand Estimates (WASDE) reports released monthly by the World Agricultural Outlook Board of USDA. Also, since China's soybean crop has been unable to keep pace with the rapid growth of domestic consumption, imports have grown rapidly to make up for the lack of domestic supply. The increasing deficit has been replaced by imports from Argentina, Brazil, and the U.S. These countries export approximately 90 percent of the world's soybeans. More importantly, China will consume 60 percent of all exported soybeans by 2011(USDA). We use the percentage change of the summation from these three countries as the proxy from China's soybean imports. In recent years, there has been special interest regarding the relationship between energy markets and agricultural commodity prices. The integration between energy and agricultural markets is accounted for via oil spot prices. We use the percentage change of crude oil price stated in Dollars per Barrel from U.S. Energy Information Administration.

We also consider the speculative and hedging influences in China's futures market, represented by trading volume. Trading volume can be used as a proxy for information flows. Trading volume is likely to be associated with speculation, since day traders or speculators trade in and out in short periods of time, and seldom hold a position for too long. Fung and Patterson (2001) find that volume increases volatility. We use the percentage change of the total volume as the exogenous variables.

Dummy variables are used to account for the seasonal effects. We use three dummies to represent planting, growing and harvesting season. Inventory season is used as base categories and thus its impact is shown in the intercept. In general, volatility increases in the spring, peaks in the summer, and declines toward the end of a year. Yang and Brorsen (1993), Chatrath et al. (2002) and Adrangi and Chatrath (2003) all conform seasonality effect in futures market. The world financial crisis became prevalent on September 15, 2008 when the major investment bank Lehman Brothers announced that it will be filing for bankruptcy. This caused many ripple effects in the financial markets, causing a credit constraint for firms and consumers. This may have effect on the volatility of the commodity markets as well. For this event, our variable CRISIS takes the value of one on the dates between September 15, 2008 and June 30, 2009 and zero for the rest.

Figure 1 shows the monthly returns to the non-GM and GM soybeans, for which the correlation coefficient is 0.81 . As expected, there is a positive correlation between the returns of soybean markets. The values of the unconditional correlations are somewhat high. Clearly the series show a great deal of variation. The non-GM soybean shows greater variation than GM. One may see that during the second half of year 2008, the returns exhibits high volatility, reflecting a financial crisis, after that, the correction can be seen in both markets. Table 1 presents descriptive statistics of the monthly returns and macro and economic variables employed in the empirical analysis. Table 2 shows the unit root test results for futures price series. As can be seen in the table, the futures prices in all markets contain a unit root, that is, these series are non-stationary. However, we can reject the existence of a unit root for the return series, computed as the 
differences of $\log$ futures prices.

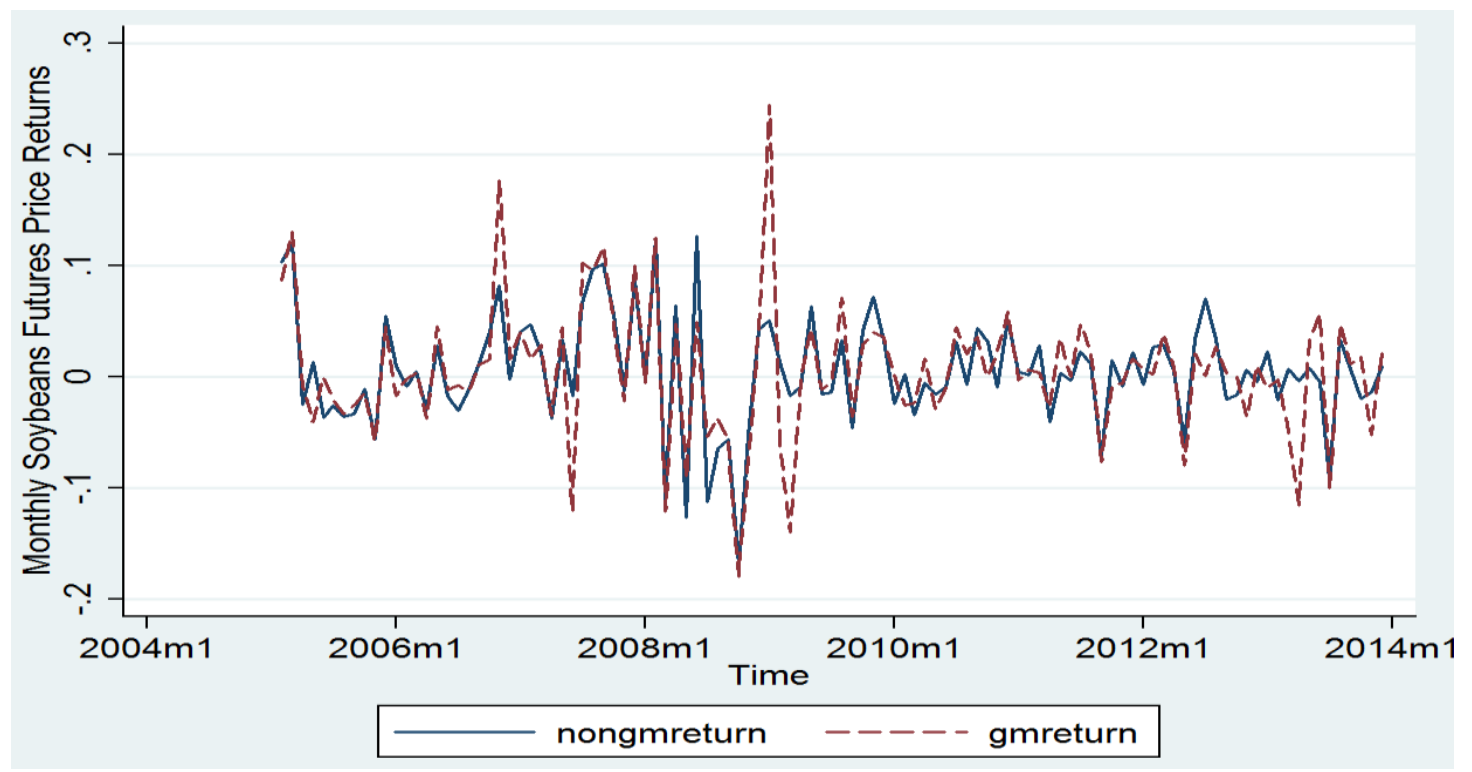

Figure 1. Monthly Non-GM and GM Soybean Price Returns

Source: DATASTREAM

Table 1. Summary Statistics

\begin{tabular}{|c|c|c|c|c|}
\hline Variable & Mean & $\begin{array}{l}\text { Standard } \\
\text { Deviation }\end{array}$ & Minimum & Maximum \\
\hline Non_GM Soybean Return & 0.571 & 5.008 & -16.965 & 12.684 \\
\hline GM Soybean Return & 0.464 & 6.028 & -18.02 & 24.484 \\
\hline$\% \Delta$ Non_GM Soybean Volume & 0.186 & 0.828 & -0.891 & 3.465 \\
\hline$\% \Delta \mathrm{GM}$ Soybean Volume & 0.534 & 3.267 & -0.898 & 32.417 \\
\hline $\begin{array}{l}\% \Delta \text { Non_GM Soybean } \text { Open } \\
\text { Interest }\end{array}$ & 0.014 & 0.227 & -0.415 & 1.452 \\
\hline$\% \Delta \mathrm{GM}$ Soybean Open Interest & 0.217 & 1.26 & -0.95 & 11.46 \\
\hline$\% \Delta$ China Soybean Production & -0.003 & 0.023 & -0.077 & 0.119 \\
\hline$\% \Delta$ China Soybean Import & 0.05 & 0.29 & -0.549 & 1.321 \\
\hline$\% \Delta$ China use/stock & -0.0004 & 0.106 & -0.359 & 0.63 \\
\hline$\% \Delta$ China IPI & -0.001 & 0.022 & -0.11 & 0.07 \\
\hline$\% \Delta$ U.S. Soybean Production & 0.001 & 0.036 & -0.139 & 0.201 \\
\hline$\% \Delta$ U.S. Soybean Stock & 0.007 & 0.205 & -0.476 & 1.13 \\
\hline$\% \Delta \mathrm{FX}$ & 0.0086 & 0.191 & -0.52 & 0.884 \\
\hline
\end{tabular}

Notes. Sample period is $01 / 01 / 2005-12 / 01 / 2013$ and total number of observations is 108. Returns are calculated as $r_{t}=100 \times\left(\ln F_{t}-\ln F_{t-1}\right)$, where $F_{t}$ is monthly settlement price of the futures contract on month $\mathrm{t}$. 
Table 2. Augmented Dickey-Fuller Unit Root Test

\begin{tabular}{lll}
\hline Variable & $\tau$ & p-value \\
\hline Futures Prices & & \\
F_nonGM & -1.49 & 0.541 \\
F_GM & -1.9 & 0.334 \\
\hline Futures Returns & & \\
R_nonGM & -6.12 & $<0.0001$ \\
R_GM & -7.69 & $<0.0001$ \\
\hline
\end{tabular}

Notes. The $\tau$ statistics and their p-values are presented for single-mean Augmented Dickey-Fuller unit root test with one lag. GM and nonGM refer to GM soybean and non-GM soybean respectively. Futures returns are calculated as $r_{t}=100 \times\left(\ln F_{t}-\ln F_{t-1}\right)$.

\section{Empirical Results}

In estimating our DCC-GARCH model for the two soybean futures, we first experiment the model with one lag, two lags, and three lags returns in the mean equation. Conditional variance equations include ARCH, GARCH parameters as well as exogenous variables discussed earlier that might have impact on volatility. To determine the appropriate length of lags, we computed the Akaike information criterion (AIC) for each model. For both soybean contracts, the one-lag model has the smallest AIC, and hence it was selected and reported here as the appropriate model. Table 3 presents the coefficient estimates and their p-values from the DCC-GARCH model. The statistical significance in this table is not indicated by asterisks, but rather by the p-value that are in parentheses under the estimates.

Table 3. DCC model results for non-GM and GM soybean futures

\begin{tabular}{|c|c|c|}
\hline Mean Eq. & Non_GM & GM \\
\hline \multirow[t]{2}{*}{ Constatnt } & -0.008 & -0.120 \\
\hline & $(0.983)$ & $(0.722)$ \\
\hline \multirow[t]{2}{*}{ Rt-1 } & 0.037 & 0.032 \\
\hline & $(0.000)$ & $(0.001)$ \\
\hline Variance Eq. & Var(Non_GM) & $\operatorname{Var}(\mathrm{GM})$ \\
\hline \multirow[t]{2}{*}{ Constant } & 2.006 & 2.199 \\
\hline & $(0.001)$ & $(0.000)$ \\
\hline \multirow[t]{2}{*}{$\mathrm{ARCH}(1)$} & 0.313 & 0.213 \\
\hline & $(0.002)$ & $(0.045)$ \\
\hline \multirow[t]{2}{*}{ GARCH(1) } & 0.224 & 0.213 \\
\hline & $(0.013)$ & $(0.072)$ \\
\hline \multirow[t]{2}{*}{ Lag_Gmreturn } & 0.002 & - \\
\hline & $(0.969)$ & - \\
\hline \multirow[t]{2}{*}{ Lag_NonGMreturn } & - & 0.132 \\
\hline & - & $(0.000)$ \\
\hline \multirow[t]{2}{*}{ Crisis } & 1.852 & 2.952 \\
\hline & $(0.005)$ & $(0.000)$ \\
\hline \multirow[t]{2}{*}{ FX } & 0.533 & -3.168 \\
\hline & $(0.768)$ & $(0.160)$ \\
\hline \multirow[t]{2}{*}{ IPI } & -7.670 & -8.150 \\
\hline & $(0.359)$ & $(0.344)$ \\
\hline \multirow[t]{2}{*}{ Non_GMVol } & 1.092 & 1.051 \\
\hline & $(0.000)$ & $(0.000)$ \\
\hline \multirow[t]{2}{*}{ GMVol } & 0.097 & 0.076 \\
\hline & $(0.070)$ & $(0.040)$ \\
\hline \multirow[t]{2}{*}{ Stock/use } & 4.749 & 5.281 \\
\hline & $(0.001)$ & $(0.042)$ \\
\hline \multirow[t]{2}{*}{ Production } & -9.883 & -20.223 \\
\hline & $(0.148)$ & $(0.001)$ \\
\hline Import & -3.284 & -2.300 \\
\hline
\end{tabular}




\begin{tabular}{lll} 
& $(0.005)$ & $(0.002)$ \\
Oil & 3.034 & -0.105 \\
& $(0.174)$ & $(0.967)$ \\
Planting & -1.154 & -0.638 \\
& $(0.767)$ & $(0.231)$ \\
Growing & -1.550 & -1.181 \\
& $(0.029)$ & $(0.007)$ \\
Harvesting & 0.026 & 0.309 \\
& $(0.968)$ & $(0.568)$ \\
DCC(1) & 0.202 & \\
DCC(2) & $(0.073)$ & \\
& 0.770 & \\
\hline LLF & $(0.000)$ & \\
LR & -491.142 & \\
& 184.768 & \\
Lyung-Box Q & $(0.000)$ & 54.346 \\
& 44.612 & $(0.045)$ \\
\hline
\end{tabular}

Note. The estimated coefficients on each term in the equation and their p-values are presented. LLf refers to loglikelihood function value. Likelihood ratio (LR) test statistics and its p-value for the null hypothesis of no exogenous variables in variance equations are given. Lyung-Box Q statistics and their p-value for the test of independence of the model residuals are presented.

\subsection{Non-GM Soybean}

The mean equation results show a constant return of -0.008 , but it is not significant. The first lagged returns is significant with a positive coefficient. The constant conditional variance is 2.006 . The ARCH parameter of 0.313 implies that positive disturbances (shocks, news) to non-GM soybean increase conditional variance by that amount. The GARCH parameter for non-GM soybean is 0.224 , showing that non-GM soybean volatility in the past period has some effect on volatility in the current period and is persistent.

Conditional variance results show that the World financial Crisis resulted in an increase in non-GM soybean price volatility. This event increases the conditional variance by 1.85 percent. For the macro variables, percent changes in FX and IPI both have insignificant effects on the conditional variance of non-GM soybean returns. A reason that the weighted FX does not influence monthly soybeans futures price volatility is that the currency CNY moves relatively at the same pace of the three other currencies. This IPI does have a significant effect could be the result that non-GM soybean is a daily commodity in China and the demand for soybean is not effected much by the macro-economic environment. Additionally, lagged shocks in GM market do not show significant effect on non-GM market.

For the speculation behavior, both percent change in non-GM and GM soybean total trading volume have significant effects on the conditional variance of non-GM soybean returns. For a one-percent increase in total trading volume of non-GM soybean, the conditional variance increase by 1.09 percent, while for a one-percent increase in GM soybean volume, the variance increases by 0.1 percent. The positive effect of volume (a proxy for speculative activity) is consistent with results in the literature. For the demand/supply side variables, both the percent change of stock/use ratio in China and the import quantity of China have significant effect on the variance as we expected. A one-percent change in the soybean stock/use ratio increases the variance by 4.75 percent while for a one-percent change in import quantity, the conditional variance of non-GM soybean decreases by 3.28 percent. Interestingly, the percent change of production of China is not statistically significant. This may due to the significant increase of soybean imports by China since the fourth quarter of 2006 has far exceeded the increase of the domestic production of China. The changes in percent change of crude oil price is not significant, either. This result agree with those obtained by Du et al. (2009), who concluded that there is no statistical evidence that the oil prices affect the variability of soybeans prices, but disagree with those obtained by Mitchell (2008) and Saghaian (2010). For the seasonality factors, only the dummy for growing time is found to be significant, showing higher volatility compared to other time. Thus we can tell that weather plays an important role in the non-GM soybean volatility in China.

\subsection{GM Soybean}

GM soybean futures have a constant return of -0.12 which is not significant. The coefficient on the first lagged return is positive. The constant conditional variance is 2.2. The ARCH parameter is 0.21 and statistically significant. The 
GARCH parameter is 0.21 , showing a small level of persistence. Similar to non-GM soybean, the financial crisis in 2008 is found to have significant impact on the conditional variance of GM soybean futures. Due to this crisis, the GM soybean variance increased by 2.92 percent, which bigger than the increase of non-GM soybean variance. This is probably because that China produces only $20 \%$ of its soybean consumption and most soybean imports are Genetic Modified. The crisis has caused severe influences in the international commodity market, the international trade of soybean thus been affected. Among macro variables, neither FX or IPI is significant, which is the same as the results for non-GM soybean. For the speculation behavior, both the trading volume of non-GM and GM soybean have a significant positive effect on variances of GM soybean.

Different from non-GM soybean, the factor of production of China shows significant effects on variances of GM soybean. A one-percent increase in production decreases the conditional variances by 20.2 percent, while a one-percent increase in stock/use ratio and import quantity in China increase the variances by 5 percent and decrease by 2.3 percent respectively. There is a huge effect of the production quantity on the volatility of GM soybean, which we can conclude the price of the imported product largely depend on the production power of the domestic product. Interestingly, the crude oil price is not statistically significant. Same as non-GM soybean, for the seasonal effect, only the growing season has significant negative effect on conditional variance. Additionally, the lagged shock of non-GM market is found to increase the conditional variance of GM soybean by 0.13 , showing spillover effects from non-GM to GM soybean market.

\subsection{Comovenment}

Finally we turn to the DCC components. The effect of time-varying correlation is captured by the coefficient DCC(1) and DCC(2), which are the parameters governing the DDC-GARCH process. DCC(1) is the sensitivity of correlations due to shocks, it reveals the speed at which the correlations matrix changes; while DCC(2) shows the persistence in the dynamic correlation, with 1 being constant correlations.

The DCC parameters in our model are significant at the $1 \%$ level, revealing that the correlation has a dynamic component. Wald test rejects the null hypothesis that $\operatorname{DCC}(1)=\mathrm{DCC}(2)=0$ at all levels $(\chi 2=1102.45)$ and $\mathrm{p}$-value $=$ 0.000 . The DCC(1) is has an estimated value of 0.2 , means the correlation is sensitive due to shocks, but not very big. DCC(2) is estimated to be 0.77. This means that there is a relatively high level of persistence over time in the correlation between these two soybeans, which is consistent with what we see in the graph. In summary, the dynamic volatilities in the returns in non-GM soybean and GM soybean markets are generally interdependent over time, sometimes very strongly.

Estimated dynamic conditional correlations within soybean markets plotted in Figure 2. The average time-varying correlations are quite similar to the unconditional correlations reported earlier which is 0.8 . The expected high to positive relationship between non-GM and GM soybeans is evident. The stable near 0.9 correlation between non-GM and GM soybeans breaks down sharply in early 2008, however, still positive and remaining so for the remaining two years. After the crisis, the correlation starts to rise in 2010 and keep the 0.9 level again till 2012. Then the correlation begins to drop again in 2013. Figure 2 confirms the time-varying properties of correlations.

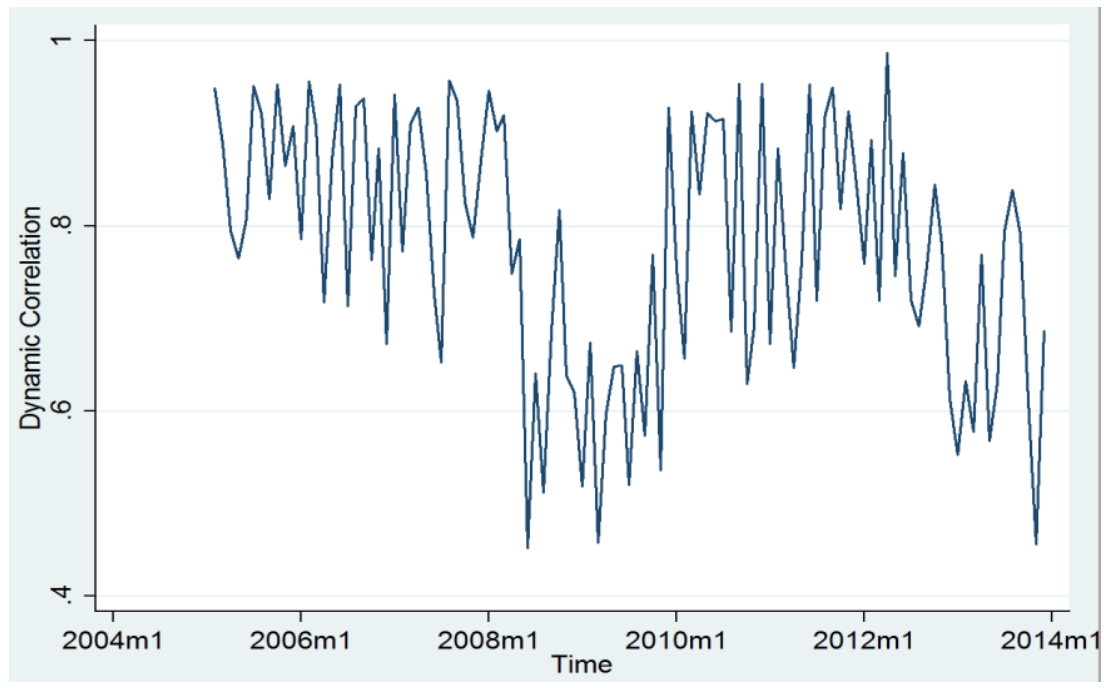

Figure 2. The estimated dynamic correlation coefficients between soybeans markets 


\section{Conclusions}

Because of the large amount of GMO soybeans imported, market participants start to pay more attention to the GMO futures markets in China. This paper analyzes the dynamic conditional correlations in the returns on these two soybean prices using multivariate DCC-GARCH model. The dynamic correlations enable a determination of whether the non-GM and GM returns are substitutes or complements, which can be used as trading strategies. Further, we analyze the impact of major economic variables on the volatility in these markets. This research provides statistical evidence that the futures prices of soybeans in China are being influenced by the increasing consumption of soybeans, the import quantity of soybean, the trading volume in futures market and weather condition during the growing season of soybean. One limitation of this study is that monthly data is used in the DCC-GARCH model due to data limitation. Daily data could be applied in future research to study the dynamic correlation between the GMO and non-GMO soybean prices in China.

Soybeans price volatility has important implications for producers, traders, and consumers. For both soybean contracts, we find some volatility persistence - as measured by the response to lagged absolute change - the effects are not large. We find statistically significant persistence in the form of an ARCH effect. The ARCH coefficients are relatively small in size, which indicates that conditional volatility does not change very rapidly. The $\mathrm{GACH}$ are not very large, either, indicating weak gradual fluctuations over time. Spillover effect was found from non-GM market to GM market.

The results of this study reveal that there is insufficient evidence to show that soybeans imports to China influenced monthly soybeans futures price volatility. For the speculation behavior, both the trading volumes of non-GM and GM soybeans have a significant positive effect on variances of the soybeans volatility. Among the macroeconomic variables considered, neither the IPI or FX affects the volatility of the two soybeans. We found the positive effect the percentage change of stock/use ratio on volatility in both soybean markets. Volatility in soybean markets is also found to change in response to the financial crisis event. The financial crisis increased both the two soybean price returns. The impact of negative shocks on GM soybean variance is larger than the impact of negative shocks in the non-GM soybean variance. China's soybean market is found to exhibit some seasonality with higher volatility in the growing season, which is from July through August.

Knowledge of the co-movements of soybean returns and volatilities is important in constructing optimal hedging and trading strategies, asset allocation and risk management. The price volatility will influence the level of capital or credit that will be required of dealers to buy and store crops; it will also increase the risk of non-performance on producer contracts. In addition, the pattern of price movements has an impact on managerial decisions of soybeans producers. First, increasing volatility will affect the level of profit and the value of the land used for production. Second, large variation of prices affects the level of revenue protection, and hence the cost of revenue insurance.

For practical purposes, our study will be helpful for understanding the value of other newly developed markets where the product traded is a close substitute for an existing market. In addition to adequate monetary policy, regulations are necessary to be created and/or enforced in order to prevent another financial calamity, as soybean volatilities were highly affected by the 2008 U.S. financial crisis.

\section{References}

Adrangi, B., \& Chatrath, A., (2003). Non-linear dynamics in futures prices: evidence from the coffee, sugar and cocoa exchange. Applied Financial Economics, 13(4), 245-256.

Antonakakis, N., Chatziantoniou, I., \& Filis, G. (2013). Dynamic co-movements of stock market returns, implied volatility and policy uncertainty. Economics Letters, 120(1), 87-92.

Bali, T. G., \& Engle, R. F. (2010). The intertemporal capital asset pricing model with dynamic conditional correlations. Journal of Monetary Economics, 57(4), 377-390.

Biotechnology. USDA (2014). http://www.ers.usda.gov/topics/farm-practices-management/biotechnol ogy.aspx.

Bollerslev, T. (1990). Modelling the coherence in short-run nominal exchange rates: a multivariate generalized ARCH model. The Review of Economics and Statistics, 72(3), 498-505.

Bollerslev, T., (1986). Generalized autoregressive conditional heteroskedasticity. Journal of econometrics, 31(3), 307-327.

Brown, P., \& Mitchell, J. (2008). Culture and stock price clustering: Evidence from The Peoples' Republic of China. Pacific-Basin Finance Journal, 16(1), 95-120.

Cai, Y., Chou, R. Y., \& Li, D. (2009). Explaining international stock correlations with CPI fluctuations and market volatility. Journal of Banking \& Finance, 33(11), 2026-2035.

Chan, K. C., Fung, H. G., \& Leung, W. K., (2004). Daily volatility behavior in Chinese futures markets. Journal of 
International Financial Markets, Institutions and Money, 14(5), 491-505.

Chatrath, A., Adrangi, B., \& Dhanda, K. K. (2002). Are commodity prices chaotic? Agricultural Economics, 27(2), 123-137.

Chen, S. T., Kuo, H. I., \& Chen, C. C. (2010). Modeling the relationship between the oil price and global food prices. Applied Energy, 87(8), 2517-2525.

Chiang, T. C., Jeon, B. N., \& Li, H. (2007). Dynamic correlation analysis of financial contagion: Evidence from Asian markets. Journal of International Money and Finance, 26(7), 1206-1228.

Creti, A., Joëts, M., \& Mignon, V. (2013). On the links between stock and commodity markets' volatility. Energy Economics, 37(2), 16-28.

Dajcman, S. (2012). Time-varying long-range dependence in stock market returns and financial market disruptions-a case of eight European countries. Applied Economics Letters, 19(10), 953-957.

Du, X., \& Hayes, D. J. (2009). The impact of ethanol production on US and regional gasoline markets. Energy Policy, 37(8), 3227-3234.

Engle, R. (2002). Dynamic conditional correlation: A simple class of multivariate generalized autoregressive conditional heteroskedasticity models. Journal of Business \& Economic Statistics, 20(3), 339-350.

Engle, R. F. (1982). Autoregressive conditional heteroscedasticity with estimates of the variance of United Kingdom inflation. Econometrica: Journal of the Econometric Society, 50(4), 987-1007.

Fung, H. G., \& Patterson, G. A. (2001). Volatility, global information, and market conditions: a study in futures markets. Journal of Futures Markets, 21(2), 173-196.

Gilbert, C. L., \& Morgan, C. W. (2010). Food price volatility. Philosophical Transactions of the Royal Society of London B: Biological Sciences, 365(1554), 3023-3034.

Goodwin, B. K., \& Schnepf, R. (2000). Determinants of endogenous price risk in corn and wheat futures markets. Journal of Futures Markets, 20(8), 753-774.

Hennessy, D. A., \& Wahl, T. I. (1996). The effects of decision making on futures price volatility. American Journal of Agricultural Economics, 78(3), 591-603.

Huang, B. W., Chen, M. G., \& McAleer, M. (2009). Modelling risk in agricultural finance: Application to the poultry industry in Taiwan. Mathematics and Computers in Simulation, 79(5), 1472-1487.

Irwin, S. H., \& Good, D. L. (2009). Market instability in a new era of corn, soybean, and wheat prices. Choices, 24(1), 6-11.

Jin, H. J., \& Frechette, D. L. (2000). Fractional integration in agricultural futures price volatilities. American Journal of Agricultural Economics. 86(2), 432-443.

Karali, B., \& Thurman, W. N. (2010). Components of grain futures price volatility. Journal of agricultural and resource economics, 35(2), 167-182.

Kenyon, D., \& McCabe, N. (1987). Factors affecting agricultural futures price variance. Journal of Futures Markets, 7(1), 73-91.

Koekebakker, S., \& Lien, G. (2004). Volatility and price jumps in agricultural futures prices-evidence from wheat options. American Journal of Agricultural Economics, 86(4), 1018-1031.

Liu, D., Williams, J., \& Jorda, O. (2002). Market-making behavior in futures markets. Doctoral dissertation, University of California, Davis.

Longin, F., \& Solnik, B. (1995). Is the correlation in international equity returns constant: 1960-1990? Journal of international money and finance, 14(1), 3-26.

Longin, F., \& Solnik, B. (2001). Extreme correlation of international equity markets. The Journal of Finance, 56(2), 649-676.

Myers, R. J., \& Hanson, S. D. (1993). Pricing commodity options when the underlying futures price exhibits time-varying volatility. American Journal of Agricultural Economics, 75(1), 121-130.

Oglend, A., \& Sikveland, M. (2008). The behaviour of salmon price volatility. Marine Resource Economics, 23(4), 507-526.

Pesaran, M. H., Schleicher, C., \& Zaffaroni, P. (2009). Model averaging in risk management with an application to futures markets. Journal of Empirical Finance, 16(2), 280-305. 
Saghaian, S. H. (2010). The impact of the oil sector on commodity prices: correlation or causation? Journal of Agricultural \& Applied Economics. 42(3), 477-485.

Schneph, R. (2008). Higher agricultural commodity prices: what are the issues? In CRS Report for Congress, No. RL34474. Washington: Congressional Research Service. http://www.grainnet.com/pdf/CRS_CommodityPrices.pdf

Silvennoinen, A., \& Thorp, S. (2013). Financialization, crisis and commodity correlation dynamics. Journal of International Financial Markets, Institutions and Money, 24, 42-65.

Sørensen, C. (2002). Modeling seasonality in agricultural commodity futures. Journal of Futures Markets, 22(5), 393-426.

Tangermann, S. (2011). Policy solutions to agricultural market volatility: A synthesis. Issue Paper, 33(1), 1-13.

Yang, J., Zhou, Y., \& Wang, Z. (2009). The stock-bond correlation and macroeconomic conditions: one and a half centuries of evidence. Journal of Banking \& Finance, 33(4), 670-680.

Yang, S. R., \& Brorsen, B. W. (1993). Nonlinear dynamics of daily futures prices: conditional heteroskedasticity or chaos? Journal of Futures Markets, 13(2), 175-191.

Zheng, Shi, et al. (2012). Price discovery in the Chinese soybean futures market: New evidence about non-GMO soybean trading. Journal of Chinese Economics, 1(1).

\section{(c) $)$ EY}

This work is licensed under a Creative Commons Attribution 3.0 License. 